\title{
A Novel 3D Model for Training on Basics of Cleft Palate Surgery: Development and Validation Study
}

\author{
AHMED S. HWEIDI, M.D.; KARIM S. MASOUD, M.D.; AHMED ZIDANE, M.Sc. and \\ MOHAMED A. GHANEM, M.D.
}

The Department of Plastic, Reconstruction, Maxillofacial Surgeries and Burn Management, Faculty of Medicine, Ain Shams University, Cairo, Egypt

\begin{abstract}
Background: Plastic surgery is considered one of the unique surgical specialties as any minimal surgical inaccuracy may cause affection of the final outcome, so simulation technology, which considered the future of plastic surgery education, should be introduced for surgical skills and knowledge transfer. Training programs have been changed to be performed in surgical skills laboratories rather than surgical theaters, in which, trainee can gain surgical skills by using training models. These laboratories have been settled not to replace the operating theater experience, but to supplement it.
\end{abstract}

Aim of Study: Is to develop a bench model for training on all crucial basic steps in cleft palate surgery, and to validate this model regarding its educational effectiveness and its ability to transfer operative skills from the bench in the skills lab to real life in operative theaters.

Material and Methods: A life-size bench model of cleft palate was customized with respect to actual size and anatomy of tissues at 18 month of age. The study period was 6 months, it entails comparing performance and operative timing of two groups of plastic surgery trainees performing primary repair of isolated cleft palate in theatre. Our model was delivered to group II only before real surgical assessment. Intraoperative evaluation of both groups of surgeons was done using the Global Rating index for Technical Skills (GRITS) and the time taken to complete the operation.

Results: Our study revealed a significant improvement in Group II GRITS score by $63.2 \%$ and significant shortening of operative time in Group II by $36.5 \%$.

Conclusion: This study provides the plastic surgery community with a novel cleft palate bench model as a validated training tool. After a single session, we observed improvement in cleft palate procedural skills, confidence, knowledge and shortening in time taken to finish the operation among trainees. Additional research is needed to assess the durability of these improvements over time, and also the benefit of additional sessions with the bench model.

Key Words: Training - Cleft palate - Validation.

\section{INTRODUCTION}

Cleft palate is considered one of the most common congenital anomalies all over the world. Uni- lateral cleft lip and palate represents the most common form (46\%), then followed by isolated cleft palate $(33 \%)$ [1]. Training of surgical repair of cleft palate may be difficult due to the following; narrow surgical field, poor visualization, needs delicate handling during palatal layers dissection, and as well as the simultaneous access needed by surgeon and assistant [2]. Most of residency programs provide skill acquisition by surgical trainer via one to one learning through a real patient. Traditional surgical learning is usually introduced by aspiring surgeons to their trainees in the operating room in the following sequence; surgical observation by trainee, then gradual assumption of the trainee to the role of trainer under supervision until the trainee developed sufficient skills and self confidence to operate independently. Finally, the trainee teaches the procedure to other junior surgeons in similar fashion [3].

This training system is successful in transferring experiences and skills from senior surgeons to junior ones, but for some ethical and medicolegality issues, searching for an alternative way of training program is needed [4].

Moreover, plastic surgery is considered one of the unique surgical specialties as any minimal surgical inaccuracy may cause affection of the final outcome, so simulation technology, which considered the future of plastic surgery education, should be introduced for surgical skills and knowledge transfer [5].

Training programs have been changed to be performed in surgical skills laboratories rather than surgical theaters, in which, trainee can gain surgical skills by using training models. These laboratories have been settled not to replace the operating theater experience, but to supplement it [6]. 
As all these training models are widely used in plastic surgery practice to improve surgical skills, it is recommended to be integrated in most of training programs of junior plastic surgeons [7].

Aim of the study: Is to develop a bench model for training on all crucial basic steps in cleft palate surgery, and to validate this model regarding its educational effectiveness and its ability to transfer operative skills from the bench in the skills lab to real life in operative theaters.

\section{MATERIAL AND METHODS}

\section{Model development:}

The model developed consists of a combination of several models described previously in literatures $[\mathbf{8 , 9 , 1 0 , 1 1 ]}$. However, fundamental refinements and modifications have been made in both manufacturing and application levels. A life-size bench model of cleft palate was customized with respect to actual size and anatomy of tissues at 18 month of age. This was facilitated by taking dental impression forms of 3 babies affected with cleft palate before performing their surgeries. To simulate the soft tissue part; we were assisted by a professional sculptor, specialized in manufacturing silicon masks for movies.

The model is composed of a hard base of polyester resin that was shaped after the hard palate skeleton using the dental impression models (Fig. 1-A). The base was coated with liquid industrial grade silicon in a single pink layer over the hard palate and the surrounding gingiva and was let to harden (Fig. 1-B).

Over the previously made hard palate a layer of rubber was added resembling the oral mucosa, an extension for the soft palate posteriorly was added and merged. This was composed of 3 silicon layers, clefted in the midline (Fig. 1-C). The oral and nasal mucosa layers (pink in color) with an embedding muscle layer (red in color) in between. A pathologic mal-insertion in the simulated muscles was considered.

The complete model was based inside a cylindrical tube resembling the oral cavity space (Fig. 1-D).

\section{Task analysis and simulation plan:}

The classic procedure of cleft palate repair was analyzed into seven main steps by one senior plastic surgeon. All steps were simulated on the model successfully in order to test the feasibility of all parts. Table (1) shows these seven steps. All steps were simulated and photographed as shown in (Fig. 2).

Table (1): All seven surgical steps.

Step 1 Marking and incising the proposed nasal layer flaps

Step 2 Dissection of the flaps, turn over and suturing in midline (nasal mucosa reconstruction)

Step 3 Dissection of the muscle layer (red silicon) and release of the abnormal insertions

Step 4 Repairing of the muscle layer in mid line

Step 5 Designing and release of the soft palate back cuts

Step 6 Designing and elevation of Hard palate mucoperiosteal flaps.

Step 7 Closure of the oral layer and packing of the donor site

\section{Validation of the Model and study design:}

The aim of the model validation was to assess its educational effectiveness and its ability to transfer operative skills from the bench to real life in operating room. Meanwhile, after approval of institutional ethics committee at Ain Shams university Hospitals, an Interventional pilot study was performed in both operating room and Plastic surgery skills and simulation lab. The study period was 6 months, it entails comparing performance and operative timing of two groups of plastic surgery trainees performing primary repair of isolated cleft palate in theatre. Our model was delivered to group II only before real surgical assessment.

Meanwhile; Trainees were divided into two groups with close levels of knowledge and experience according to their residency program. The trainees were randomly assigned into the two groups by randomly generated computer numbers.

Group I $(n=5)$ in which trainees were assessed directly in life surgery (as a part of our conventional apprenticeship training model under supervision of senior staff) without bench model training. On the other hand; Trainees in Group II $(n=5)$ were assessed while performing live surgery, only after receiving training at the skills lab using our model within the task analysis in 2 hours time frame. The training on the model was performed during an in house training course beforehand for all subjects (trainees) in group 2. The setting of the course in the plastic surgery skills lab and the working station for each candidate is shown in (Fig. 3). 

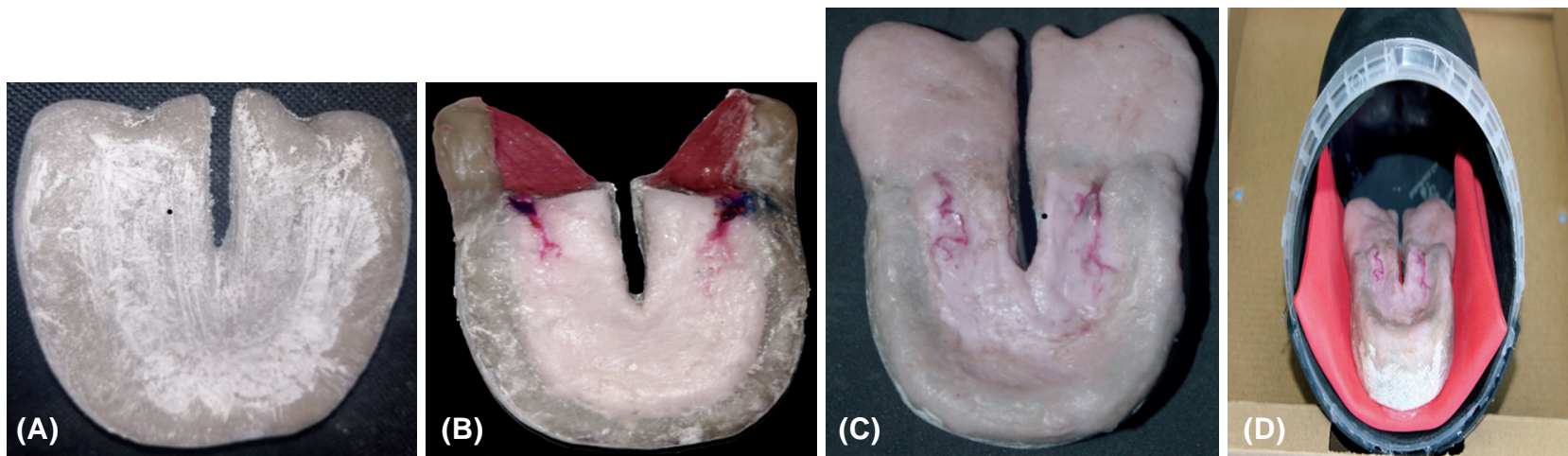

Fig. (1): Stages of development of the training model.

(A): Hard base of polyester resin shaped after the hard palate after hardening.

(B): Adding of the mucoperiosteal layer over the hard palate by rubber and muscle layer in soft palate by red colored silicon.

(C): After adding of the mucosa layers in the soft palate by pink colored silicon.

(D): Placing the complete model inside a cylindrical tube resembling the oral cavity space.
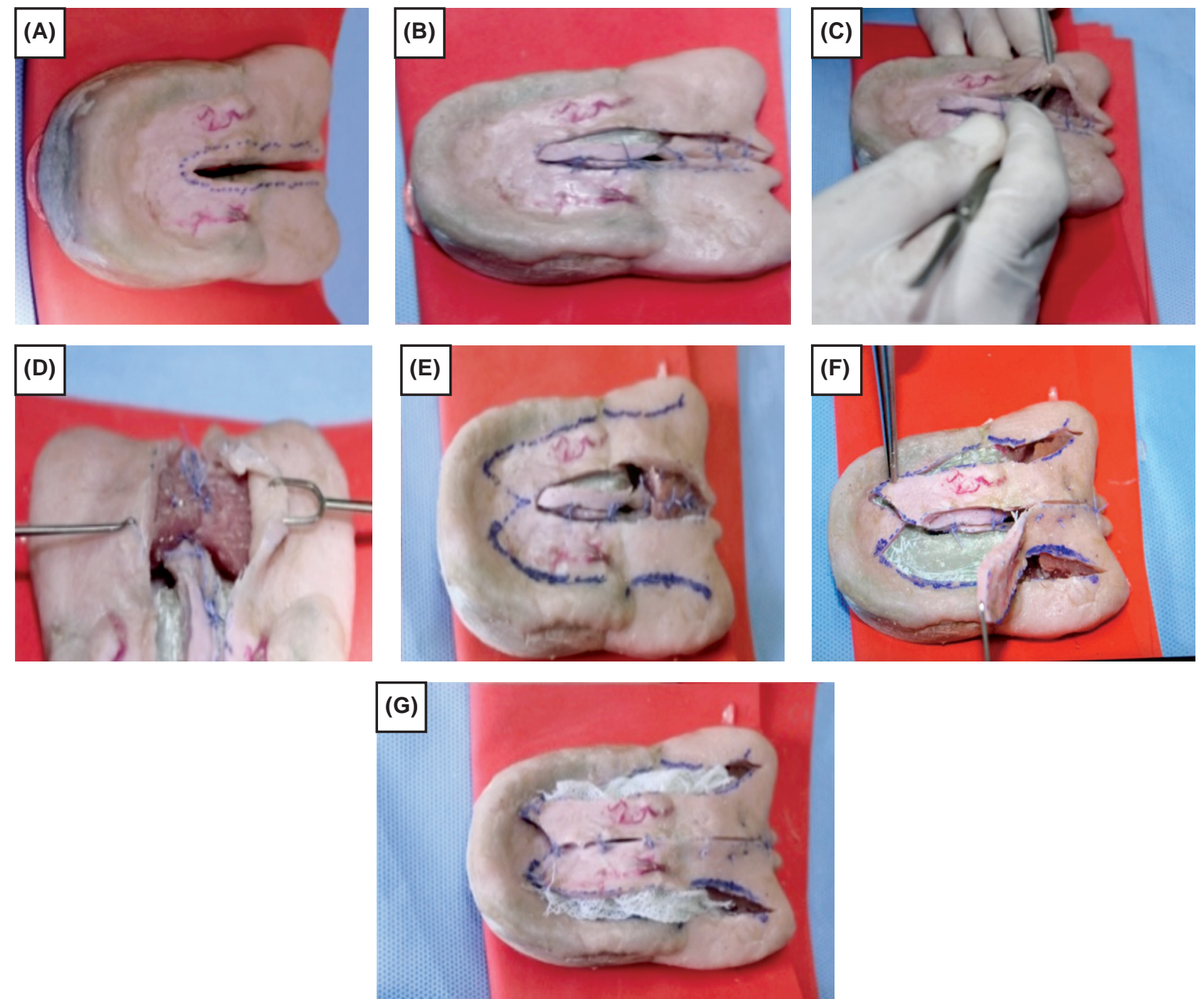

Fig. (2): Task analysis and simulation plan. 
Fig. (3): Course setting in the Plastic surgery skills lab.

(A): Instruments used by each candidate.

(B): Working station setting.

(C): Placing sutures in depth.

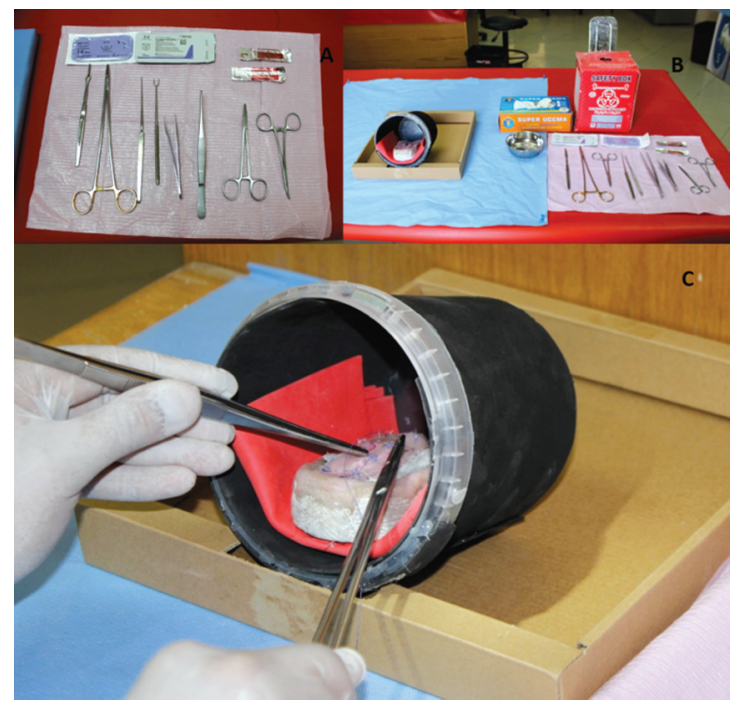

Intraoperative evaluation of both groups of surgeons was done using the Global Rating index for Technical Skills (GRITS) (Fig. 4) and the time taken to complete the operation [12]. Assessment

was performed by a single staff member for all trainees. The assessor measured the surgical time for all candidates in both groups, as well as their performance using GRITS scale check list.

\begin{tabular}{|c|c|c|c|}
\hline \multicolumn{4}{|l|}{ Respect for Tissue } \\
\hline 1 & 2 & 3 & $4 \quad 5$ \\
\hline $\begin{array}{l}\text { Frequent unnecessary force on } \\
\text { tissues or caused damage by } \\
\text { inappropriate use of instruments }\end{array}$ & & $\begin{array}{c}\text { Careful handling of tissue but } \\
\text { occasionally caused inadvertent } \\
\text { damage }\end{array}$ & $\begin{array}{l}\text { Consistently handled tissue } \\
\text { appropriately with minimal } \\
\text { damage to tissues }\end{array}$ \\
\hline \multicolumn{4}{|l|}{ Tme and Motion } \\
\hline 1 & 2 & 3 & 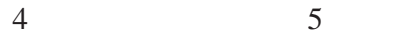 \\
\hline Many unecessary moves & & $\begin{array}{l}\text { Efficient time/motion but some } \\
\text { unnecessary moves }\end{array}$ & $\begin{array}{c}\text { Clear economy of movement. } \\
\text { Maximum efficiency }\end{array}$ \\
\hline \multicolumn{4}{|l|}{ Instrument Handling/Knowledge } \\
\hline 1 & 2 & 3 & 4 \\
\hline $\begin{array}{l}\text { Tentative/awkward moves or } \\
\text { inappropriate use }\end{array}$ & & $\begin{array}{l}\text { Competent use of instruments, } \\
\text { occasionally awkward }\end{array}$ & $\begin{array}{c}\text { Fluid moves with instruments. } \\
\text { No awkwardness }\end{array}$ \\
\hline \multicolumn{4}{|l|}{ Flow of Operation } \\
\hline 1 & 2 & 3 & $4 \quad 5$ \\
\hline $\begin{array}{l}\text { Frequently stopped, seemed unsure } \\
\text { of next move }\end{array}$ & & $\begin{array}{l}\text { Some forward planning, } \\
\text { reasonable progression }\end{array}$ & $\begin{array}{c}\text { Obviously planned course, } \\
\text { effortless flow }\end{array}$ \\
\hline \multicolumn{4}{|l|}{ Knowledge of Specific Procedure } \\
\hline 1 & 2 & 3 & $4 \quad 5$ \\
\hline $\begin{array}{l}\text { Deficient knowledge. Required } \\
\text { specific instruction at most steps }\end{array}$ & & $\begin{array}{c}\text { Knew all important steps of } \\
\text { operation }\end{array}$ & $\begin{array}{l}\text { Demonstrated familiarity with } \\
\text { all steps of operation }\end{array}$ \\
\hline \multicolumn{4}{|l|}{ Use of Assistants (if applicable) } \\
\hline 1 & 2 & 3 & 4 \\
\hline $\begin{array}{l}\text { Consistently placed assistants } \\
\text { poorly or failed to use }\end{array}$ & & $\begin{array}{l}\text { Appropriate use of assistants } \\
\text { most of the time }\end{array}$ & $\begin{array}{l}\text { Strategically used assistants to } \\
\text { best advantage at all times }\end{array}$ \\
\hline \multicolumn{4}{|l|}{ Communication Skills } \\
\hline 1 & 2 & 3 & $4-5$ \\
\hline $\begin{array}{l}\text { Frequent problems working with } \\
\text { team or fails to communicate }\end{array}$ & & $\begin{array}{l}\text { Appropriate communication } \\
\text { with team most of the time }\end{array}$ & $\begin{array}{c}\text { Co-ordinates surgical team in } \\
\text { a superior manner }\end{array}$ \\
\hline
\end{tabular}

Fig. (4): Global Rating index for Technical Skills (GRITS) [12]. 
All infants referred for surgery were eligible to enter the trial if after obtaining an informed written consent from parents. Ten infants were included, of both genders. Inclusion Criteria entailed, isolated cleft palate, medically fit for surgery at 12 months and parent approval with written informed consent. On the other hand; Infants with severe developmental delay or submucous cleft palate were excluded.

\section{Statistical analysis:}

Recorded data were analyzed using the statistical package for social sciences, version 20.0 (SPSS Inc., Chicago, Illinois, USA). Quantitative data were expressed as mean \pm standard deviation (SD). Qualitative data were expressed as frequency and percentage.

\section{The following tests were done:}

Independent-samples $t$-test of significance was used when comparing between two means.

- Mann Whitney U test: For two-group comparisons in non-parametric data.

- Chi-square $\left(\mathrm{x}^{2}\right)$ test of significance was used in order to compare proportions between qualitative parameters.

Table (2): GRITS scoring and operative time in (group I).

\begin{tabular}{cll}
\hline \multirow{2}{*}{$\begin{array}{c}\text { Cases } \\
\text { No. }\end{array}$} & \multicolumn{2}{c}{ Group I } \\
\cline { 2 - 3 } & GRITS & Time (min) \\
\hline 1 & 17 & 115 \\
2 & 15 & 120 \\
3 & 20 & 95 \\
4 & 20 & 90 \\
5 & 23 & 100 \\
\hline Mean & 19.00 & 104.00 \\
\pm SD & 2.58 & 10.24 \\
\hline
\end{tabular}

- The confidence interval was set to $95 \%$ and the margin of error accepted was set to 5\%. So, the $p$ value was considered significant as the following:

- Probability ( $p$-value).

- $p$-value $\leq 0.05$ was considered significant.

- $p$-value $\leq 0.001$ was considered as highly significant.

- $p$-value >0.05 was considered insignificant.

\section{RESULTS}

In this study, we compared two groups of surgeons, each group operated on 5 patients undergoing cleft palate repair with or without the receiving training on our bench model.

The results of the present study are demonstrated in the following Tables and Figures.

Correlation between both groups according to GRITS score as showed a significant improvement in Group II score by $63.2 \%$ (Table 4).

Correlation between both groups according to operative time showed significant shortening of time in Group II by $36.5 \%$ (Table 5 ).

Table (3): GRITS scoring and operative time in (group II).

\begin{tabular}{cll}
\hline \multirow{2}{*}{$\begin{array}{c}\text { Cases } \\
\text { No. }\end{array}$} & \multicolumn{2}{c}{ Group II } \\
\cline { 2 - 3 } & GRITS & Time $(\min )$ \\
\hline 1 & 26 & 75 \\
2 & 30 & 60 \\
3 & 33 & 70 \\
4 & 32 & 65 \\
5 & 34 & 60 \\
\hline Mean & 31.00 & 66.00 \\
\pm SD & 1.41 & 3.82 \\
\hline
\end{tabular}

Table (4): Correlation between means of GRITS score in both groups.

\begin{tabular}{lllllll}
\hline \multirow{2}{*}{ GRITS } & \multirow{2}{*}{$\begin{array}{c}\text { Group I } \\
(\mathrm{n}=5)\end{array}$} & $\begin{array}{c}\text { Group II } \\
(\mathrm{n}=5)\end{array}$ & \multicolumn{5}{c}{ Paired sample $t$-test } \\
\cline { 5 - 7 } & & & Mean Diff. & Change $\%$ & $t$-test & $p$-value \\
\hline Range & $15-23$ & $26-34$ & & & & \\
Mean \pm SD & $19.00 \pm 3.08$ & $31.00 \pm 3.16$ & 12.0 & $63.20 \%$ & -6.074 & $<0.001^{* *}$ \\
Median (IQR) & $20(5.5)$ & $32(5.5)$ & & & & \\
\hline
\end{tabular}

Using: Paired Sam $t$-test. $\quad * * p$-value $<0.001 \mathrm{HS}$.

Table (5): Correlation between means of operative time in both groups.

\begin{tabular}{|c|c|c|c|c|c|c|}
\hline \multirow{2}{*}{ Time (min) } & \multirow{2}{*}{$\begin{array}{l}\text { Group I } \\
(\mathrm{n}=5)\end{array}$} & \multirow{2}{*}{$\begin{array}{l}\text { Group II } \\
(\mathrm{n}=5)\end{array}$} & \multicolumn{4}{|c|}{ Paired sample $t$-test } \\
\hline & & & Mean Diff. & Change $\%$ & $t$-test & $p$-value \\
\hline Range & $90-120$ & $60-75$ & & & & \\
\hline Mean \pm SD & $104.00 \pm 12.94$ & $66.00 \pm 6.52$ & -38.0 & $-36.54 \%$ & 5.864 & $<0.001 * *$ \\
\hline Median (IQR) & $100(25)$ & $65(12.5)$ & & & & \\
\hline
\end{tabular}

Using: Paired Sam $t$-test. $\quad * * p$-value <0.001 HS. 


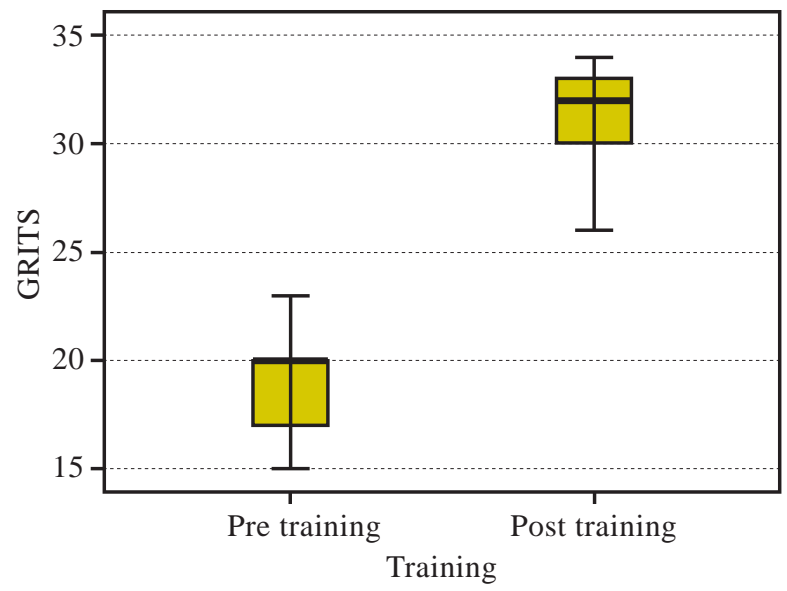

Fig. (5): Box plot of GRITS for both groups.

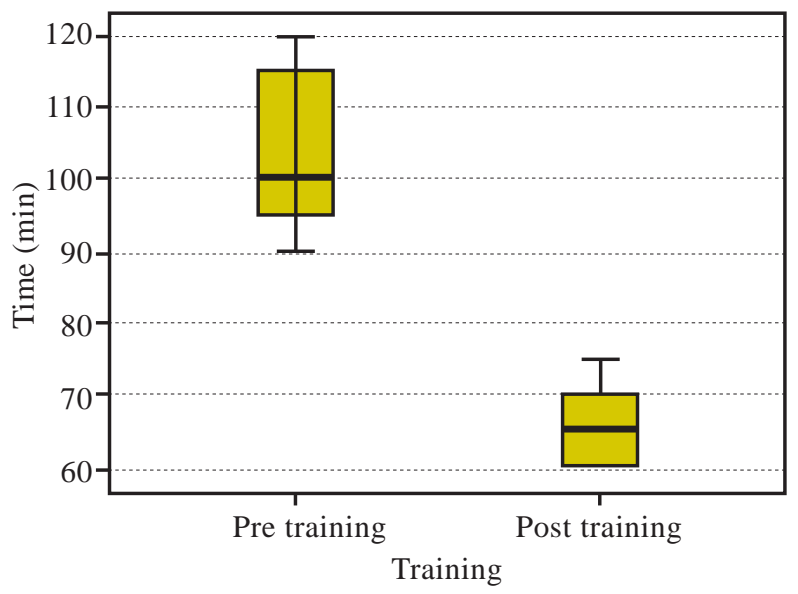

Fig. (6): Box plot of operative time for both groups.

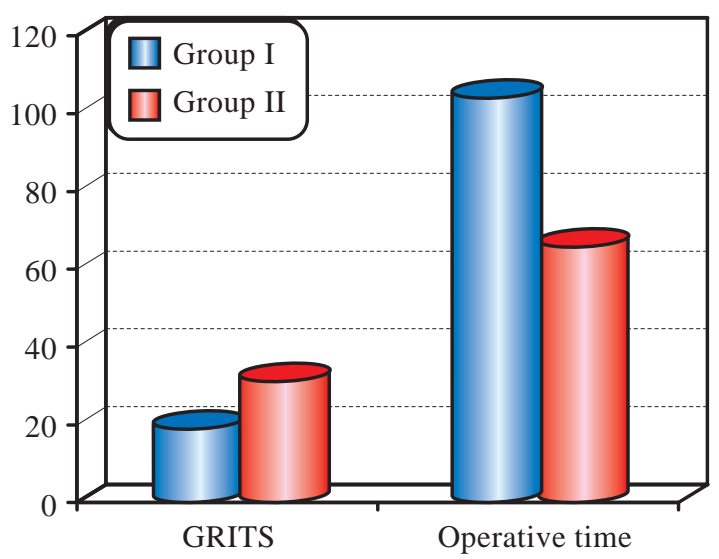

Fig. (7): Correlation between means of GRITS score and operative time in both groups.

\section{DISCUSSION}

Development of Operative skills is the cornerstone in any surgical training program. Although apprenticeship model of "see one, do one, teach one" [13] has been successful in transferring skills and knowledge from one generation to the next, several authors have suggested that this model is no longer acceptable to either their profession or to the well informed public $[\mathbf{1 3 , 1 4 , 1 5}]$. The introduction of reduced working hours, medico-legal and financial constraints in the last two decades result in less intra-chances for surgical trainees. This challenge has encouraged the usage of skills laboratories for teaching technical skills in different surgical specialties. Such Laboratories have been developed not to replace the operating room experience, but rather to supplement it [16].

There is an increase in work being done in the development of simulation models for many subspecialties in plastic surgery, from simple suturing models to complex virtual reality simulators. The literature review however, revealed that the process of developing a simulator and introducing it to a training program needs to move forward from a random to a more structured pattern to ensure whether the skills learned on the bench can be transferred to real life in theatre. This process is referred as Training model validation [17].

Cleft palate surgery is difficult for surgeons due to many unique factors like; working in a small cavity, limited access, poor visualization, delicate tissue handling, muscle dissection, suturing in depth and simultaneous access required by the surgeon and the assistant [1,2]. Hence we decided to develop a simulator model to overcome these difficulties that meet the trainees in our department in this particular type of surgeries.

Few cleft palate models were proposed in literature before for training purpose. The first was designed in 2007 by Vadodaria and his colleagues [8]. It was composed of simple circular structure that was the size of a 6 month old infant mouth resembling the mouth component; with soft palate layers made from latex for both oral and nasal layers with the muscle layer in between made from red foam. All components were placed inside a plastic cup to offer stabilization. This model offered a simple idea about the cleft palate surgery with affordable and available materials.

Although being easily reproduced, it showed low fidelity, in which few anatomical details were needed, this was considered in our model. Moreover, Validation of the model and its educational effectiveness was not measured objectively.

In 2009, Nagy and his colleagues [9] proposed a Life-size model of the oral cavity of a cleft palate patient using other materials such as alginate impression material, impression plaster, paper tem- 
plate among others. It simulated the intra-oral circumstances and the unique features of cleft palate surgery: Small cavity, limited access, awkward angles, delicate tissue handling, use of an operating microscope, and suturing in depth. In addition, the model is life size, and one can design the flaps and perform the simulation in a high fidelity simulation circumstances.

Although having high fidelity, the main shortcoming of this model is that it is difficult to be assembled and replicated. Actually, a dental laboratory facilities are needed for assembly (e.g., to prepare the plaster models from alginate impression material, to duplicate the cleft palate, to prepare the definitive plaster hard palate model), and the first trial showed that assembly is time consuming.

In 2013, Senturk and his colleagues [10] described the simplest cleft palate simulator from a simple sponge placed inside plastic water bottle. This model despite being easy to assemble with almost no cost at all, its low fidelity and hinders its ability to simulate real surgery. In our opinion it can just give a very shallow idea of suturing in tight spaces with no tissue dissection or other surgical procedures.

In 2016, Pinho and his colleges [18] proposed a three-dimensional (3D) cleft palate model to improve understanding and conceptualization of cleft palate repair, as well as offer deliberative and repetitive hands on training of basic cleft palate repair skills before applying surgical techniques on live patients. It composed of a life sized maxillary dental cast with plates of ethylene-vinyl acetate placed over in a manner resembling the normal layers of the soft palate all placed inside a plastic cup to simulate the oral cavity. They proposed a 3D, homemade, simple, inexpensive, portable, reproducible, and life sized bench model of the oral cavity of a pediatric cleft palate patient with materials resembling the fragility of the palate soft tissues. However again, this was not validated or tried on training setting to assess its educational effectiveness.

Recently in 2018, Cheng and colleges [11] performed a palatoplasty workshop consisting of a didactic session on cleft palate anatomy and repair followed by a simulation session. Participants completed a procedural confidence questionnaire and palatoplasty knowledge test immediately before and after the workshop. Although confidence among trainees was shown to be improved after the workshop, there weren't any data regarding the model components or how to assemble. In addition, a questionnaire is only a week and subjective method of validation.

In Our study, a 3D high fidelity model for training on Cleft palate surgery was proposed. We provided step by step manual for how to do with simple materials. Moreover, we have validated our model objectively by assessing the performance of two groups of trainees performing supervised life surgery. One group received model training and the other did not. The results was in favor to the bench model group; where there was a statistically significant improvement regarding GRITS score for technical skills. In addition to Statistically significant decrease in time needed to complete the procedure in real surgery.

Conclusion: This study provides the plastic surgery community with a novel cleft palate bench model as a validated training tool. After a single session, we observed improvement in cleft palate procedural skills, confidence, knowledge and shortening in time taken to finish the operation among trainees. Additional research is needed to assess the durability of these improvements over time, and also the benefit of additional sessions with the bench model.

\section{REFERENCES}

1- Hopper R.A., Cutting C. and Grayson B.: Cleft lip and palate. Grabb and Smith's Plastic Surgery. $6^{\text {th }}$ Edition. Philladelphia: Lippincott Williams and Wilkins, 201, 2007.

2- Denadai R. and Toledo A.P.: Martinhão Souto LR. Basic plastic surgery skills training program on inanimate bench models during medical graduation. Plastic Surgery International, 2012.

3- Reznick R.K. and MacRae H.: Teaching surgical skillschanges in the wind. New England Journal of Medicine, 355 (25): 2664-9, 2006.

4- Desender L.M., Van I.H., Aggarwal R., Vermassen F.E. and Cheshire N.J.: Training with simulation versus operative room attendance. The Journal of Cardiovascular Surgery, 52 (1): 17-37, 2011.

5- Sarker S. and Patel B.: Simulation and surgical training. International Journal of Clinical Practice, 61 (12): 21205, 2007.

6- McDougall E.M.: Surgical education in the $21^{\text {st }}$ century: Hit or miss? JSLS: Journal of the Society of Laparoendoscopic Surgeons, 8 (4): 297, 2004.

7- Wanzel K.R., Matsumoto E.D., Hamstra S.J. and Anastakis D.J.: Teaching technical skills: Training on a simple, inexpensive, and portable model. Plastic and Reconstructive Surgery, 109 (1): 258-64, 2002.

8- Vadodaria S., Watkin N., Thiessen F. and Ponniah A.: The first cleft palate simulator. Plastic and Reconstructive Surgery, 120 (1): 259-61, 2007. 
9- Nagy K. and Mommaerts M.Y.: Advanced s (t) imulator for cleft palate repair techniques. The Cleft PalateCraniofacial Journal, 46 (1): 1-5, 2009.

10- Sentürk S.: The simplest cleft palate simulator. Journal of Craniofacial Surgery, 24 (3): 1056, 2013.

11- Cheng H., Podolsky D.J., Fisher D.M., Wong K.W., Lorenz H.P., Khosla R.K., Drake J.M. and Forrest C.R.: Teaching palatoplasty using a high-fidelity cleft palate simulator. Plastic and Reconstructive Surgery, 141 (1): 91e-8e, 2018.

12- Doyle J.D., Webber E.M. and Sidhu R.S.: A universal global rating scale for the evaluation of technical skills in the operating room. Am. J. Surg. May, 193 (5): 5515; discussion 555, 2007.

13- Rohrich R.J.: "See one, Do one, Teach one"an old adage with a new twist. Plast. Reconstr. Surg., 118 (1): 257-8, 2006.

14- REZNICH R.K. and MacRAE H.: Teaching surgical skills-
Changes in the wind. N. Engl. J. Med., 355 (25): 26649, 2006.

15- Grantcharov T.P.: Is virtual reality simulation an effective training method in surgery? Nat. Clin. Pract Gastroenterol. Hepatol., 5 (5): 232-3 Epub 2008 Apr 1, 2008.

16- ROSEN J.M., LONG S.A., McGRATH D.M. and GREER S.E.: Simulation in Plastic Surgery training and education: The path forward. Plast. Reconst. Surg., 123 (2): 729-38; discussion 39-40, 2009.

17- HWEIDI A.S., ELBARBARY A., ABDALAZIZI Y., SAFE I. and McARTHUR P.: Assessment and Development of Training models in Plastic Surgery. MD Thesis, Faculty of Medicine, Ain Shams University, 2012.

18- PINHO A.S., RAPOSO-AMARAL C.A., RAPOSOAMARAL C.E. and DENADAI R.: Cleft palate surgical skills training using an alternative synthetic bench model. Chinese Medical Journal, 129 (11): 1382, 2016. 